\title{
Presencia andaluza del Instituto Central de Conservación y Restauración: El Proyecto Santa Lucía (1972-1982)
}

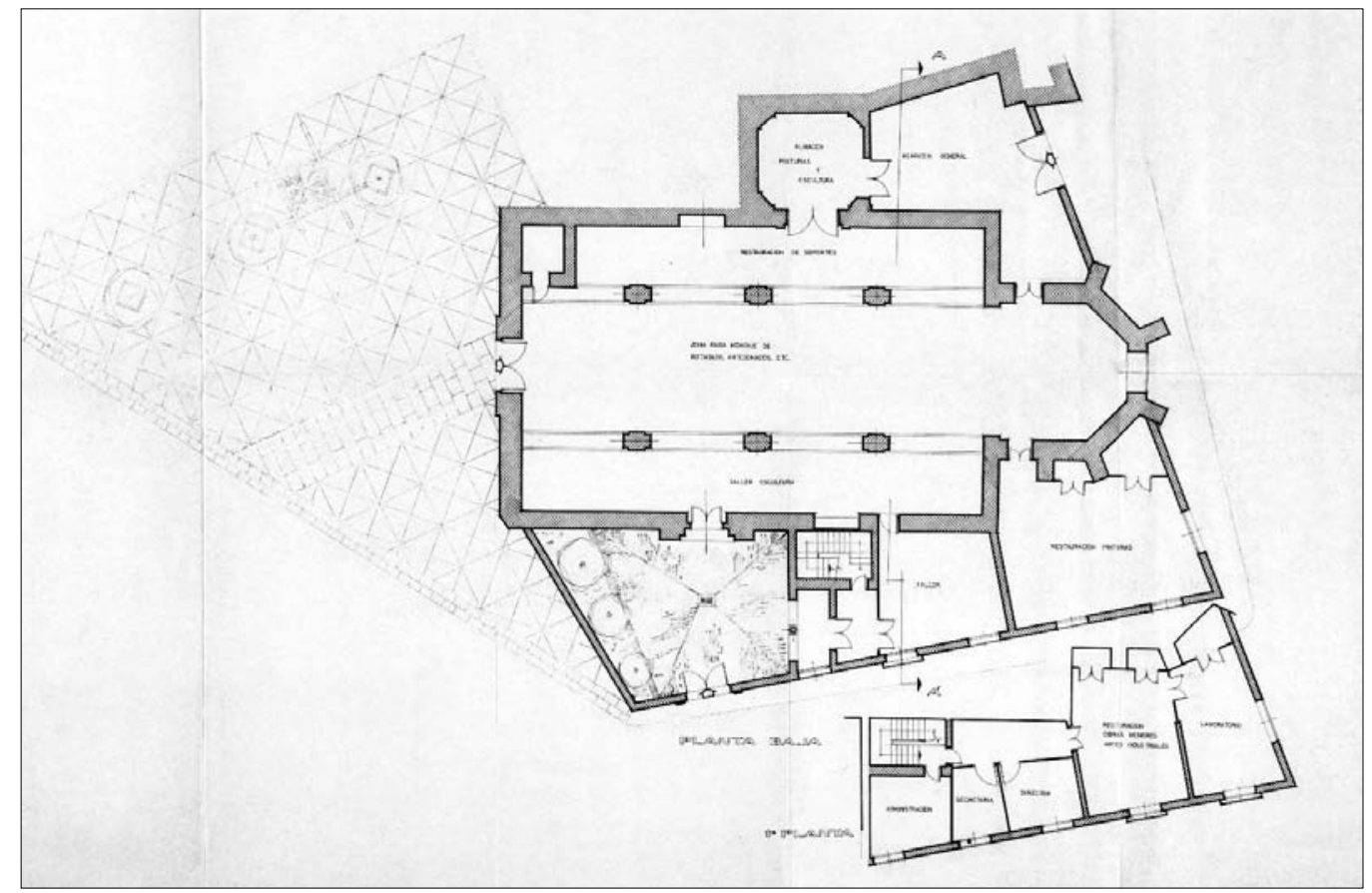

Lorenzo Pérez del Campo

Recientemente se han celebrado los diez años de existencia del Instituto Andaluz del Patrimonio Histórico. Esta efemérides ha permitido analizar diferentes modelos organizativos nacionales y extranjeros, conocer la naturaleza, alcance y objetivos de estos organismos especializados de la Administración y reflexionar sobre su papel en relación con determinadas políticas públicas de tutela del patrimonio histórico !.

Pero el hilo de esta reflexión también ha permitido hacer historia en relación con alguno de los proyectos que los poderes públicos diseñaron en diferentes momentos y coyunturas políticas en un intento de dotar a Andalucía de alguna institución especializada en la conservación y restauración de obras de arte y bienes artísticos. Uno de estos proyectos, no suficientemente estudiado hasta ahora, fue el formulado el res de Sevilla durante el primer debate de investidura de la historia de la Comunidad por el candidato Rafael Escuredo. Entre los objetivos formulados en su discurso de investidura hizo referencia al impulso a la Cultura andaluza como uno de los ejes de la acción de gobierno mediante la creación de varios instrudramático andaluz, la orquesta sinfónica andaluza, el centro andaluz de lectura, el centro coordinador de archivos, el patronato de museos andaluces, la Fundación Blas Infante, el Instituto de Cultura Andaluza y el INSTITUTO DE RESTAURACIÓN Y DEFENSA DEL dería a estas unidades la ejecución de las políticas tendentes a consolidar la Cultura en el territorio "co14 de julio de 1982 en un salón de los Reales Alcázamentos administrativos: casas de Cultura, el centro PATRIMONIO HISTÓRICO-ARTÍSTICO. Correspon-
Fig. I. Iglesia de Santa Lucía. Planta. Estado en 1978 (según R. Manzano)
I. "Los Institutos de Patrimonio y su papel en el próximo milenio". Jornadas desarrolladas en el Instituto Andaluz del Patrimonio Histórico los días 12, 13 y 14 de abril de 2000 

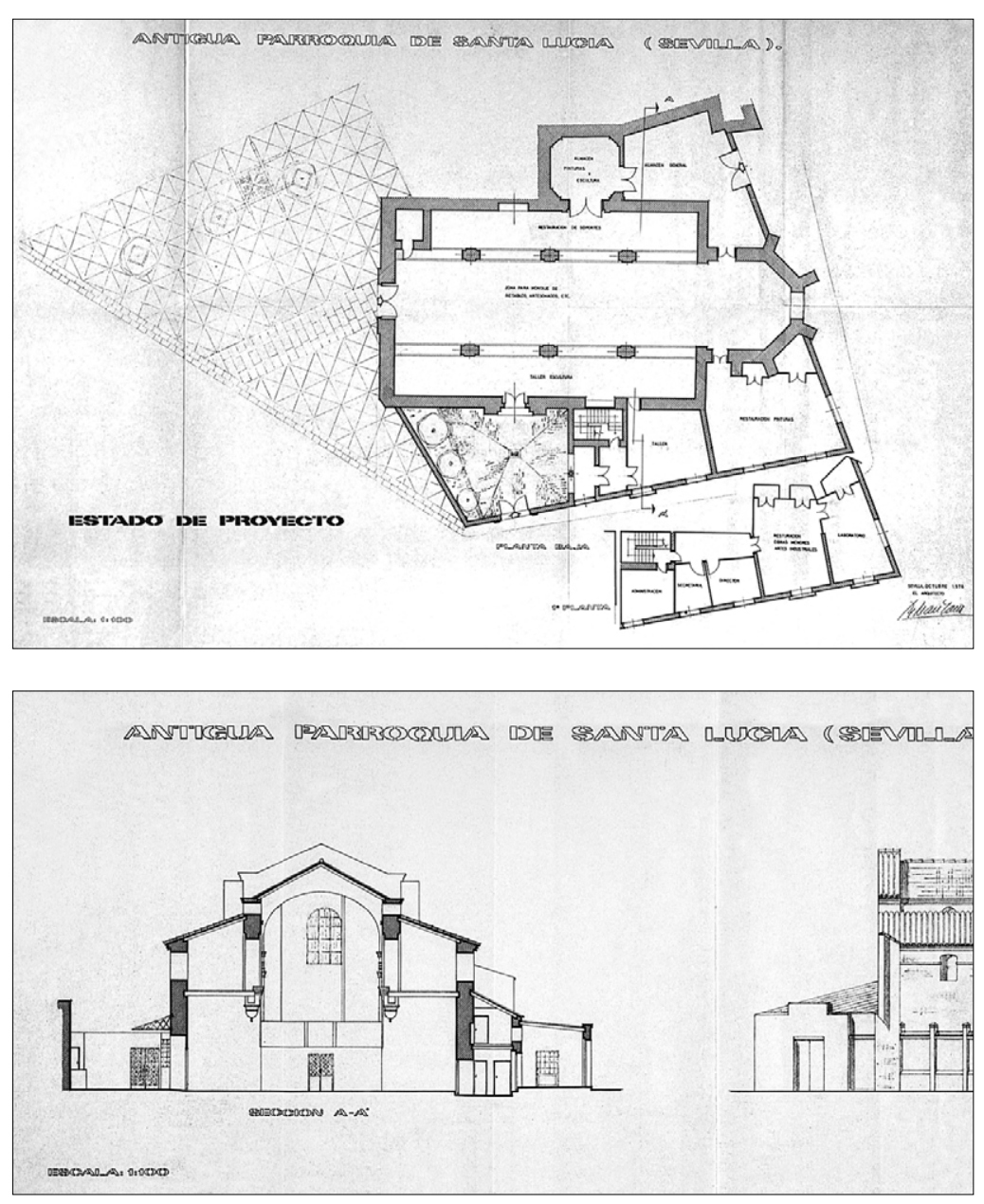

Fig. 2. Proyecto de instalación de talleres del Instituto Central de Obras de Arte en la Ex Iglesia de Santa Lucía. Sevilla. Arq. Rafael Manzano (1978). Distribución espacial del programa de usos.

Fig. 3. Proyecto de instalación de Talleres del Instituto Central de Obras de Arte en la Ex Iglesia de Santa Lucía-Sevilla. Arq. Rafael Manzano (1978). Sección de la iglesia con distribución de Talleres.

2. Diario de Sesiones del Parlamento de Andalucía. Primera Legislatura. Núm. 3 (14.07.1982). Pág. 65

3. Creado por Decreto 107/1989, de 16 de mayo. BOJA núm. 46, de 13 de junio

4. Boletín Oficial del Estado de 7 de diciembre de 196 mo Comunidad Histórica diferenciada, lo que es, a su vez, un factor determinante de la revitalización de la cultura de la Nación" 2.

Buena parte de las citadas instituciones se crearon inmediatamente, no así el Instituto de Restauración que hubo de esperar hasta 1989 en que vería la luz el actual I.A.P.H. ${ }^{3}$.

Otro ejemplo anterior al citado, del que sin duda fue antecedente, y muy característico de la utopía cultural, es el proyecto que entre 1972 y 1982 permitió la creación en Sevilla de una sección filial del entonces Instituto de Conservación y Restauración de Obras de Arte postulando la ubicación de sus Talleres, Laboratorios y dependencias administrativas en la antigua iglesia de Santa Lucía, que fue expropiada al efecto. La empresa, cuyo diseño respondió a las estrategias de la política cultural tardofranquista, sobrevivió al régimen anterior, pues también gozó del apoyo político de los gobiernos de la Unión de Centro Democrático hasta mayo de 1982, lo que explica la amplia cronología apuntada. Los costes económicos del proyecto superaron los 8 millones de pesetas de la época.

La génesis del proyecto de Sección Andaluza del ICCROA ha de relacionarse necesariamente con los contenidos del Decreto 24/5/|96/4 por el que se creaba el Instituto Central de Restauración y Con- servación de obras y objetos de arte, arqueología y etnología dependiente de la Dirección general de Bellas Artes del Ministerio de Educación Nacional, siguiendo el modelo institucional de la administración italiana. Este Instituto, que venía a sustituir a la Junta de Conservación y Restauración de Pintura y otras Obras de Arte antiguo creada por Real Orden de 14 de abril de 1924, tenía como fines básicos:

a) La restauración de toda clase de obras pertenecientes al patrimonio artístico nacional

b) La restauración de objetos arqueológicos y etnológicos de colecciones oficiales

c) La restauración de los materiales y elementos artísticos de los Monumentos Nacionales

d) La restauración de obras y objetos de arte, arqueología y etnología pertenecientes a otras entidades públicas y privadas y a particulares, para lo que en cada caso se establecerán los conciertos oportunos

e) La realización de análisis físicos, químicos y bacteriológicos que sean necesarios para conocer la constitución de los objetos y obras de arte, arqueología y etnología que deban ser restaurados y para determinar el tratamiento adecuado en cada caso

f) La práctica de cuantos trabajos sean necesarios para la conservación de obras de arte y objetos arqueológicos y etnológicos, tales como forrado y desmonte de pinturas, extracción y traslado de mosaicos, operaciones conducentes a la conservación de pinturas, maderas, piedras, objetos de metal, cerámica, tejidos, cueros. etc.

g) La formación de un archivo en el que consten gráfica y literariamente, los antecedentes, ensayos y trabajos realizados y los resultados de las restauraciones verificadas

h) El estudio de los medios y técnicas más recientes y eficaces para llevar a cabo las finalidades de restauración y conservación, para lo que se establecerán relaciones con otros laboratorios y centros de investigación nacionales y extranjeros con los que se tratará de concertar un intercambio de experiencias y de métodos

i) La formación y preparación de técnicos que puedan servir adecuadamente a las finalidades expresadas, así como a las que se refieren a la instalación y conservación de las colecciones en los Museos y en otros lugares donde deban exhibirse.

El programa de usos de la institución comprendía laboratorios de química, física, radiografía y fotografía, la escuela de Procedimientos y Arte de la Restauración y Museología, archivo, biblioteca especializada y los siguientes talleres de restauración:

- Pintura

- Escultura

- Mosaicos

- Elementos arquitectónicos

- Mobiliario

- Tejidos y tapices

- Vidrieras

- Metales

- Cerámica

- Objetos arqueológicos y etnológicos 
Estos talleres funcionarían en la sede central del Instituto o en las Secciones Filiales localizadas estas últimas en provincias. La reorganización del Instituto formulada en el Decreto de 23 de julio de 1971 no afectó a la organización de los talleres ni a los contenidos sustantivos del marco de actuación técnica del servicio así como tampoco a la figura de la Sección Filial cuya virtualidad se mantuvo a pesar de no haberse hecho uso de la misma durante la primera década de existencia del ICCROA funcionando, tan sólo los talleres de la Sede Central madrileña.

Esta situación cambió a partir de la promulgación del Decreto 2239/1972, de 21 de julio, que creaba una Sección Filial del Instituto con sede en Sevilla en atención a la importancia del patrimonio histórico andaluz y sus necesidades conservativas ${ }^{5}$. La nueva Sección Filial estaría dirigida por una Comisión Delegada de la Comisión Directiva del Instituto a que hacía referencia el artículo séptimo del Decreto 2093/I97 I con funciones ejecutivas y de gerencia de acuerdo con lo descrito en el citado Decreto. Un año más tarde, otra Sección Filial con sede en Santiago de Compostela se crearía por Decreto de 17 de mayo de 1973.

Resuelta la creación de la Filial sevillana era necesario buscar inmueble en el que ubicar la sede institucional, encontrándose idóneo el edificio de la antigua iglesia de Santa Lucía entonces de propiedad particular. E edificio fue declarado de utilidad pública a efectos de expropiación forzosa, adquirido por el Estado y adscrito a la Dirección general del Patrimonio Cultural y Artístico.

\section{El edificio}

Aluden a la iglesia de Santa Lucía determinadas referencias documentales de 1285, por lo que se trata de una de las parroquias más antiguas de Sevilla. La creación de la iglesia se vincula con la acción planificadora del arzobispo Don Remondo (1259-1286), el primer gran organizador de la administración diocesana, quién determinó su ubicación en las inmediaciones de la Puerta del Sol, junto a las murallas de la ciudad sobre una de las antiguas mezquitas hispalenses.

La arquitectura del edificio corresponde al lenguaje mudéjar y su tipología se encuadra en lo que Angulo ha dado en denominar "tipo parroquial sevillano", clasificación en la que incluyó, además, a los inmuebles de las iglesias San Julián y Santa Marina. Para el citado historiador del arte los edificios de este tipo definen un modelo arquitectónico de nueva orientación, cuyas formas regirán en adelante el interior de los templos sevillanos de tres naves hasta bien entrado el siglo XVI. Las soluciones lingüísticas que caracterizan al modelo se concretan en el uso de pilares de ladrillo de sección rectangular con resaltes apenas perceptibles en su lado más ancho, presbiterio ochavado con bóveda gótica de cantería, naves laterales terminadas en plano, fachada de los pies con tres grandes óculos y portada de cantería intensamente abocinada con pobrísima decoración animada y cornisa horizontal de canes 6 .

El terremoto de 1355 parece afectó a su fábrica pues consta testimonio documental de actividad edilicia en el edificio relación con aquel. A principios del siglo XVIII se remodeló el presbiterio. Perdió su condición de parroquia a principios del siglo XVI, actuando como filial de la de San Marcos. Años más tarde recuperó esta condición sirviendo de escenario al bautizo del hijo del marqués de Tarifa e Isabel Pinelo, mas tarde conocido por San Juan de Ribera.

Tal vez el elemento más significativos del edificio es la portada, analizada por el profesor Rafael Comez (1990), y que en la actualidad sirve de acceso a la iglesia de Santa Catalina, lugar al que fue trasladada en 1929-1930 según proyecto del arquitecto Juan Talavera y Heredia ${ }^{7}$.

El inmueble mantuvo su uso religioso hasta comienzos del siglo XIX. En octubre de 1868 es incautado por la recién constituida Junta Revolucionaria Municipal. Mediante Acuerdo Capitular de 3 de noviembre de ese año fue concedida por el Ayuntamiento a la "Tertulia Democrática. Reunión de Artesanos Honrados" sirviendo de local social para el desarrollo de las actividades estatutarias de esta asociación cívica A principios del siglo $X X$ la adquiere el erudito $y$ coleccionista sevillano Rafael González Abreu, instalándose en ella una fábrica de fósforos, peligrosa actividad que ocasionó variados daños a la fábrica, entre ellos, el hundimiento de la torre. En los años treinta sirvió como sala de proyecciones cinematográficas y más recientemente como taller de reparación de vehículos a motor.

Abandonada esta actividad industrial, el estado del edificio era de ruina. Un informe del arquitecto Rafael Manzano (noviembre de 1978) nos dice que "prácticamente se han hundido parcial o totalmente las cubiertas de sus tres naves y de las dependencias inmediatas, y por lo tanto, solamente la organización mural es susceptible de utilización ulterior. En lo que respecta a sus volúmenes exteriores falta el cuerpo de campana de la torre... y los añadidos en su delantera afean notablemente el conjunto. El ábside central ha sido cercenado en parte por un muro moderno y las ruinosas dependencias exigen una reordenación en el sentido de valoración del conjunto como en el de organización funcional para nuevo destino".

Por Real Orden de 9 de febrero de 1931 el inmueble fue declarado Monumento Histórico Artístico Nacional 9 .

\section{El programa de usos}

El programa de necesidades formulado por el Servicio de Monumentos de la Dirección General de Bellas Artes, Archivos y Bibliotecas en base al Decreto 24I5, estableció la necesidad de contar con áreas de conser-
5. Boletín Oficial del Estado de 24 de agosto de 1972

6. ANGULO INNÍGUEZ (1932) Arquitectura mudéjar sevillana, siglos XIII, XIV, XV. Pág. 32

7. COMEZ RAMOS (1990)

"La portada de la iglesia de Santa Lucía en Sevilla: iconografía y cronología". Revista Laboratorio de Arte n 3 , págs. 33-44

\section{TASSARA Y GONZÁLEZ}

(1919): "Apuntes para la historia de la revolución de setiembre del año 1868 en la ciudad de Sevilla. Noticias de los templos y

Monumentos derribados y de las Iglesias clausuradas, de orden de la Junta Revolucionaria, durante el mando del Ayuntamiento popular interino". Sevilla, 1919. Págs. 77 a 82

9. Gaceta de Madrid de 17 de febrero de 1931. En virtud de lo establecido en la Disposición Adicional Primera de la Ley 16/1985, de 25 de junio, del Patrimonio Histórico Español, los bienes declarados histórico-artísticos pasaron a tener la consideración y a denominarse "Bien de Interés Cultural". 
$\longleftarrow$
$\square$

vación y restauración de bienes muebles en diferentes soportes y tamaños. También se necesitaban almacenes para obras de arte pequeño y gran formato, un almacén de material diverso, un laboratorio y un área de dirección, secretaría y administración.
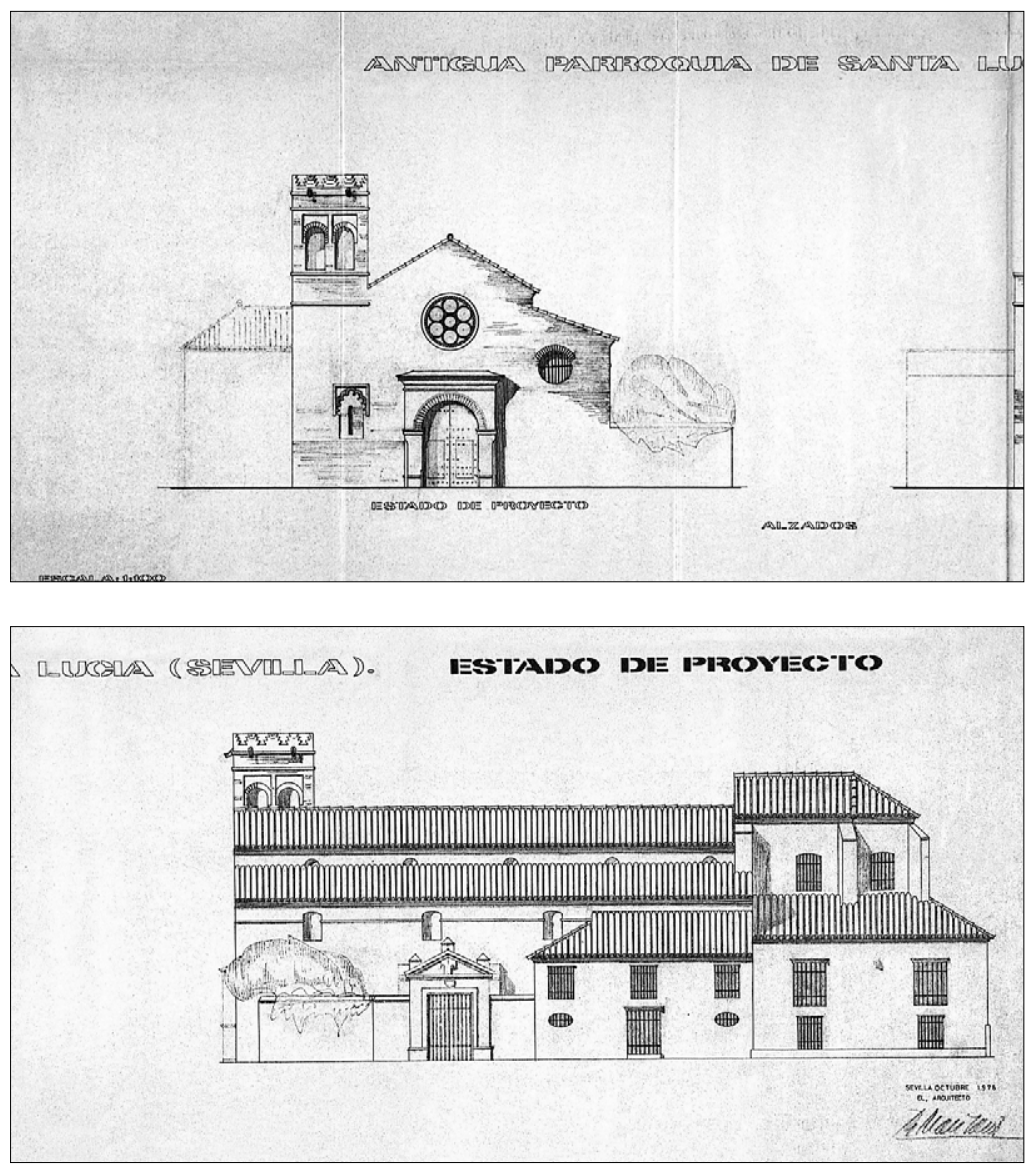

Fig. 4. Propuesta de fachada. Ex Iglesia de Santa Lucía. Arq. Rafael Manzano (1978).

Fig. 5. Propuesta de alzado lateral. Ex Iglesia de Santa Lucía. Arq. Rafael Manzano (1978).

10. Archivo General de la Administración. Caja 93.957

11. Archivo General de la Administración. Caja 70.713

12. Archivo General de la Administración. Caja 70.793

13. VAZQUEZ CONSUEGRA (1986) Cien edificios de Sevilla susceptibles de reutilización para usos institucionales

14. COMEZ RAMOS (1990)
Para materializar el programa, la Dirección general del Patrimonio Artístico, Archivos y Museos encargó el oportuno proyecto de "adaptación de talleres del Instituto Central de Obras de Arte en la ex-Iglesia de Santa Lucía de Sevilla" al arquitecto Rafael Manzano Martos con un presupuesto de contrata de 4.281 .823 ptas. y plazo de ejecución de seis meses ${ }^{10}$.

El proyecto fue aprobado el 12 de febrero de 1979, adjudicándose la obra por Orden Ministerial de 30 de abril de 1979. Los trabajos se realizaron entre mayo y setiembre de ese año. Con carácter previo a la fase de obra que comentamos, la Dirección general de Bellas Artes realizó sendas actuaciones en 1972 1' y 1975 12, ambas también responsabilidad del citado arquitecto. Respectivamente, estas campañas acometieron la consolidación mural y estructural del inmueble, permitiendo la conservación general del mismo, pero no actuaron en la ordenación interior. En octubre de 1978 la estructura espacial de la antigua iglesia era caótica presentando un aspecto extremadamente compartimentado fruto de las intervenciones realizadas por exigencias de las necesidades de las diferentes industrias que a lo largo del siglo XX ocuparon el edificio (Fig. I). Las tres naves se encontraban tabicadas de forma irregular arbitrando hasta seis espacios diferentes de muy distinta superficie. Un colgadizo de madera compartimentaba el espacio de las dos naves laterales en altura. En situación similar se encontraban las antiguas dependencias parroquiales, la Capilla Sacramental y el ábside en el que había desaparecido el segmento de plementería central, actuando en otra época como zaguán de entrada a la industria.

La propuesta formulada en el proyecto (Fig.2) recuperaba el sentido unitario longitudinal del espacio de las naves de la iglesia incluyendo tres talleres de conservación y restauración. La nave central, a la que se incorporaba el ábside, dejaba de tener acceso al exterior, y se destinaba a zona de montaje de retablos y artesonados con ingreso directo para vehículos desde la entrada principal, disponiéndose un suelo de adoquines, adecuado para tal fin. En la nave lateral E. se ubicaba el Taller de Escultura, también con acceso desde el exterior, mientras que en la nave lateral $O$. se disponía el Taller de Restauración de Soportes.

En la antigua Capilla Sacramental, de planta cuadrangular achaflanada, se programó el Almacén de Pinturas y Esculturas con doble comunicación hacia el TaIler de Soportes y hacia el Almacén General dispuesto en una construcción adosada a la Sacramental aprovechando un antiguo patio. Este Almacén disponía de una puerta para acceso de vehículos y debía actuar a modo de muelle de carga y descarga.

En el otro lado del ábside se construyó un amplio Taller de Restauración de Pinturas con sendos espacios independientes destinados fundamentalmente a labores de barnizado. El Taller de Material Arqueológico y Etnológico ocupaba el espacio contiguo. Estos dos Talleres ocupaban la planta baja del edificio de antiguas dependencias parroquiales. En la primera planta se diseñaron el Taller de Restauración de Obras Menores y Artes Industriales y el Laboratorio. También se reservaron espacios para la dirección, secretaría y administración.

A pesar de este esfuerzo, los diversos Talleres nunca llegaron a constituirse. Finalizado el proceso de transferencias de competencias en materia de Patrimonio Histórico a las Comunidades Autónomas, el Instituto Central de Conservación y Restauración, y sus secciones filiales, fueron suprimidos por Real Decreto 565/1985, de 24 de abril.

Más recientemente (noviembre de 1982) se realizaron nuevas obras de conservación en el edificio según proyecto del arquitecto Laffarga Osteret, que consistieron, básicamente, en "restauración de los paños de fábrica, bovedillas de hormigón, construcción de forjado de piso y cubierta de la sala junto al ábside y en cubrición con tejas. Revestido de techos en naves" 13. En mayo de 1984 este último arquitecto planteó el uso cultural público del edificio. La propuesta no fue atendida destinándose el inmueble a local de ensayo de la Orquesta Filarmónica de Sevilla 14. 